\title{
Mortality from Diabetic Nephropathy in the United Kingdom
}

\author{
A. Moloney ${ }^{1}$, W. M. G. Tunbridge ${ }^{2}$, J. T. Ireland ${ }^{3}$ and P.J. Watkins ${ }^{1 *}$ \\ 'Diabetic Department, King's College Hospital, London, ${ }^{2}$ Newcastle General Hospital, Newcastle upon Tyne and \\ ${ }^{3}$ Southern General Hospital, Glasgow, UK
}

\begin{abstract}
Summary. Deaths in diabetic subjects dying under 50 years of age in the United Kingdom during 1979 have been analysed with special reference to diabetic nephropathy. Fifteen percent of 447 deaths were from nephropathy. Uraemic deaths from nephropathy were particularly common in those whose diabetes was diagnosed under 31 years old, and responsible for over one-quarter of deaths in this age group. Most deaths from nephropathy occur before 30 years' duration of diabetes and are rare in those of longer duration, suggesting that some diabetic patients are more and others less prone to this complication. There were more men than women in a ratio of ap-
\end{abstract}

proximately $1.3: 1$. Severe retinopathy is usually present in end-stage renal failure causing blindness in one out of three cases, and impaired vision in a further one out of three. Blind patients were not otherwise more severely affected by diabetic complications than others. It is estimated that approximately three-quarters of the diabetic subjects who develop end-stage renal failure from nephropathy may be suitable for dialysis or transplantation.

Key words: Diabetes mellitus, diabetic nephropathy, mortality.
Development of persistent proteinuria during the course of long-term diabetes is a bad prognostic feature heralding death from renal failure in younger patients or from cardiovascular disease in older subjects [1]. The exact proportion of young diabetic patients who die from renal failure is not known, although from a recent Danish study it is estimated to be about one-fifth of those whose diabetes was diagnosed under 31 years of age [2]. It has been predicted in the USA that during the 1980 s renal failure from diabetes will become the fourth commonest source of new dialysis patients [3].

Diabetic subjects reaching terminal renal failure are usually beset with multiple diabetic complications, notably severe retinopathy and arterial disease. In the past, they have been rejected from dialysis or transplan-

\footnotetext{
* On behalf of the Medical Services Study Group (Royal College of Physicians of London) and The British Diabetic Association. Study group: M. Tunbridge (Northern), Project Chairman; J. Bingle (Yorkshire); J. Ward (Trent), J. Day (East Anglia); R. Elkeles (NW Thames); A. Cudworth (NE Thames); P. Watkins, C.Lowy (SE Thames); G.Spathis (SW Thames); R. Hill (Wessex); D. Hockaday, J.Lister (Oxford); C. Burns-Cox (S Western); L. Alexander, M. FitzGerald (W Midlands); P.Adnitt (Mersey); S.Oleesky (N Western); T. Hayes (Wales); J. Ireland (Scotland); D. Hadden (Northern Ireland); D. Appleton (Statistician), T. Tiplady (Specialist in Community Medicine), (Newcastle-upon-Tyne); Sir Cyril Clarke, A. W.G. Whitfield (Medical Services Study Group, Royal College of Physicians); A. Bloom (British Diabetic Association)
}

tation programmes because of these complications, although during the last decade workers in Minneapolis have demonstrated that these treatments are quite often successful [4]. The proportion of diabetic patients with end-stage renal failure who are not overwhelmed by the complications of their disease and therefore possible candidates for such active treatment is not known.

The present enquiry was designed to discover the proportion of diabetic patients who die annually from renal failure before the age of 50 years and, by analysis of the accompanying diabetic complications, to ascertain their suitability for dialysis or transplantation. It has also enabled us to discover new facets of the natural history of diabetic nephropathy. The information has been obtained from the investigation conducted jointly by the Medical Services Study Group of the Royal College of Physicians of London and the British Diabetic Association in which deaths of diabetic subjects under 50 years of age occurring during 1979 were examined. Full details of this study have been reported elsewhere [5].

\section{Method of Study}

Any death certificate with diabetes mellitus or hypoglycaemia or diabetic ketoacidosis appearing in any position on the certificate was identified by the Area Medical Officer to whom certificates are sent 
Table 1. Deaths from nephropathy, and the prevalence of nephropathy at death in relation to age at diagnosis of diabetes

\begin{tabular}{|c|c|c|c|c|c|c|}
\hline \multirow{2}{*}{$\begin{array}{l}\text { Age at } \\
\text { diagnosis } \\
\text { (years) }\end{array}$} & \multirow[t]{2}{*}{$\begin{array}{l}\text { Total } \\
\text { deaths }\end{array}$} & \multicolumn{2}{|c|}{ Nephropathy deaths } & \multicolumn{2}{|c|}{$\begin{array}{l}\text { Nephropathy present } \\
\text { at death }\end{array}$} & \multirow{2}{*}{$\begin{array}{l}\text { Protein- } \\
\text { uria } \\
\text { only } \\
\text { (No) }\end{array}$} \\
\hline & & (No) & $(\%)$ & (No) & $(\%)$ & \\
\hline$<10$ & 46 & 13 & 28 & 22 & 48 & 0 \\
\hline$<20$ & 134 & 41 & 31 & 64 & 48 & 3 \\
\hline$<30$ & 210 & 57 & 27 & 96 & 46 & 4 \\
\hline$\leqslant 50$ & 447 & 69 & 15 & 113 & 25 & 18 \\
\hline
\end{tabular}

a 'Proteinuria only' refers to those patients in whom proteinuria was recorded but whose retinal status was not known. All patients described as 'nephropathy present' were known to have retinopathy
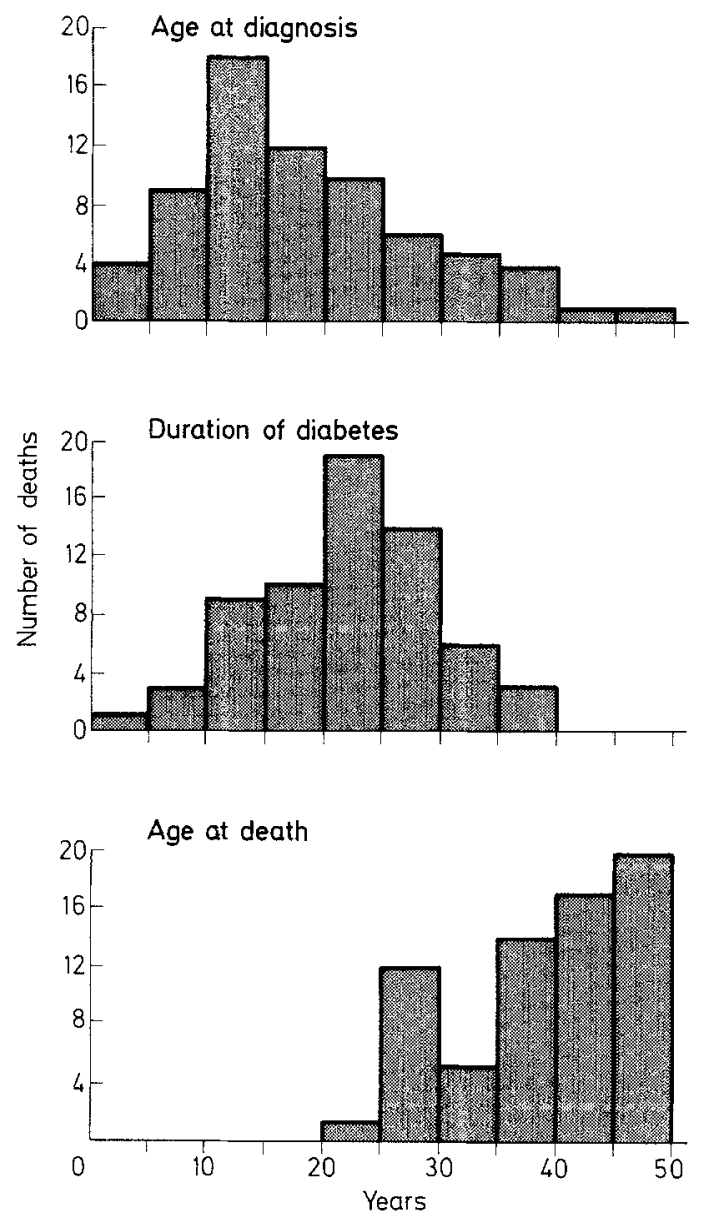

Fig. 1. Distribution of age at diagnosis, duration of diabetes and age at death of 69 patients with diabetic nephropathy

before being forwarded to the Office of Population Census and Surveys. The area medical officer sent a copy of the certificate to the appointed co-ordinator in each region who then approached the general practitioner and/or hospital consultant concerned, seeking information relating to the death and asking for the loan of the patient's notes. The information was treated as confidential and no approach was made to the patient's relatives. A questionnaire was completed by the regional co-ordinator after examination of the case records: the coordinators, all of whom were experienced consultant physicians with a special interest in diabetes, determined the cause of the death from the records. Neither the names of the patients nor of the attendant doctors were on the questionnaires which were scrutinised by at least two other co-ordinators.

\section{Selection of Patients}

Four-hundred and fifty-three deaths of diabetic patients under 50 years of age were reported during 1979 . Of these, 447 were suitable for the present analysis. Cardiovascular disease (ischaemic heart disease and strokes) was the major cause of death (185 cases, $41 \%$ ) and was followed by renal failure ( 75 cases, $17 \%)$. That reported renal failure deaths were actually from uraemia was established by the regional co-ordinator's scrutiny of the notes using the usual biochemical criteria (raised urea and creatinine).

Six of the renal failure deaths were excluded from the present analysis because they were due to non-diabetic kidney disease (systemic lupus, acute renal failure, renal failure in steroid-induced diabetes, renal failure following aorto-iliac bypass, renal failure from ileal bladder, and one non-insulin dependent diabetic who was already in renal failure without retinopathy when diabetes was diagnosed). It seemed likely that the remaining 69 renal failure deaths were due to diabetic nephropathy: thus, all but two were known to have had proteinuria for more than 1 year (range 1-16 years), and none had died from acute renal failure. Histological diagnosis of glomerulo-sclerosis was obtained in only six cases by biopsy and four at post mortem. Of 64 cases in whom the appearance of the fundi was reported, all had retinopathy (see below).

Diabetic nephropathy in patients who died from non-renal causes was defined as the presence of proteinuria for more than 1 year, (range 1-15 years), together with diabetic retinopathy; cases in which proteinuria alone was present (with fundi normal or unreported) have been documented separately (Table 1).

\section{Results}

\section{Nephropathy Deaths}

There were 69 nephropathy deaths; 40 were men and 29 were women. The average age at diagnosis of diabetes was $18 \pm 10$ years (mean \pm SD) and was the same in both sexes (Fig 1). Most (59 of the 69 cases, $86 \%$ ) were diagnosed before 31 years of age and all but one were insulin-dependent. Only 10 cases were diagnosed above this age, four of whom were non-insulin-dependent. More than one-quarter of all deaths in those diagnosed under 31 years were from nephropathy (59 of $218 ; 27 \%$; Table 1) compared with only one-sixth (69 of 447 cases, $15 \%$ ) in the whole group.

The mean duration of diabetes at the time of death was $21 \pm 7$ years and the mean age at death $39 \pm 7$ years (Fig.1). Few patients died within 10 years of diagnosis (Figs. 1 and 2), the exceptions being the four non-insulin-dependent patients who were over 30 years of age at onset of diabetes. Amongst those diagnosed under 15 years of age ( 30 cases) very few patients (five) died from renal failure after more than 30 years of diabetes. Details of this group are given in Table 2 and Figure 2; they show that there were fewer nephropathy deaths than expected after 30 years of diabetes.

Retinopathy was present in all of the 64 patients in whom the fundi could be seen; 52 of the $64(81 \%)$ had proliferative changes. Of all 69 nephropathy cases, 23 $(33 \%)$ were totally blind and a further $25(36 \%)$ had impairment of vision (ie, inability to read a newspaper); ten $(14 \%)$ were blind in one eye only.

Assessment of neuropathy in this survey was subjective and imprecise, but thought to be present in about 
half of the patients. However, foot ulcers were common and occurred in 18 cases $(26 \%)$ with mean duration of diabetes of 19 years (range: 7-39 years). They occurred more often in those dying after 39 years of age than before $(41 \%$ versus $9 \%)$.

Gangrene was reported in eight cases and amputations in five cases. One woman developed gangrene of the fingers even though the affected arm had never been used for shunt or fistula construction.

Symptomatic major vascular disease (angina, myocardial infarction, stroke, and/or claudication) was observed to be present in 16 cases (23\%); this total does not include those whose records made no mention of these problems nor those with asymptomatic vascular disease. Hypertension was usually present even before the terminal illness, with a diastolic pressure $100 \mathrm{mmHg}$ or greater in $55(80 \%)$ and 105 or more in $37(54 \%)$. Although 50 patients $(72 \%)$ received hypotensive treatment, only four achieved a diastolic pressure below $100 \mathrm{mmHg}$.

The number of major diabetic complications (namely stroke, foot ulceration or gangrene, ischaemic heart disease or blindness) increased with age at death. Thus two or more of these complications were present in six of 13 cases $(46 \%)$ of those dying between 20 and 29 years, 10 of 19 cases $(53 \%)$ dying between 30 and 39 years and 26 of $37(70 \%)$ dying between 40 and 50 years. However, the presence of complications amongst the 23 blind patients was not greater than amongst the other 46 patients.

Only nine patients (five men and four women) received dialysis (five haemodialysis, two peritoneal dialysis) or transplantation (five patients received eight kidneys), some also being dialysed before or after transplantation.

\section{Nephropathy and Cardiovascular Disease in Patients Diagnosed Under 31 Years of Age} (Tables 2 and 3)

Patients diagnosed under 31 years of age ( 218 cases) have been analysed separately because many of those diagnosed in the later decades had short-term non-insulin-dependent diabetes associated with cardiovascular disease. Almost equal numbers ( 59 and 66 , Table 3 ) died from nephropathy and cardiovascular disease respectively, which together account for just over half of the deaths.

Nephropathy was present in just under half of these younger patients, or 98 of the 218 patients (Table 3 ). Nearly two-thirds of the nephropathy patients (59 of 98) died from renal failure and have already been described. Of the remaining 39 nephropathy cases, the majority (24) died from cardiovascular disease (Table 3). The commonest single cause of death amongst diabetic patients without nephropathy was cardiovascular disease ( 29 of $82,35 \%$ ).

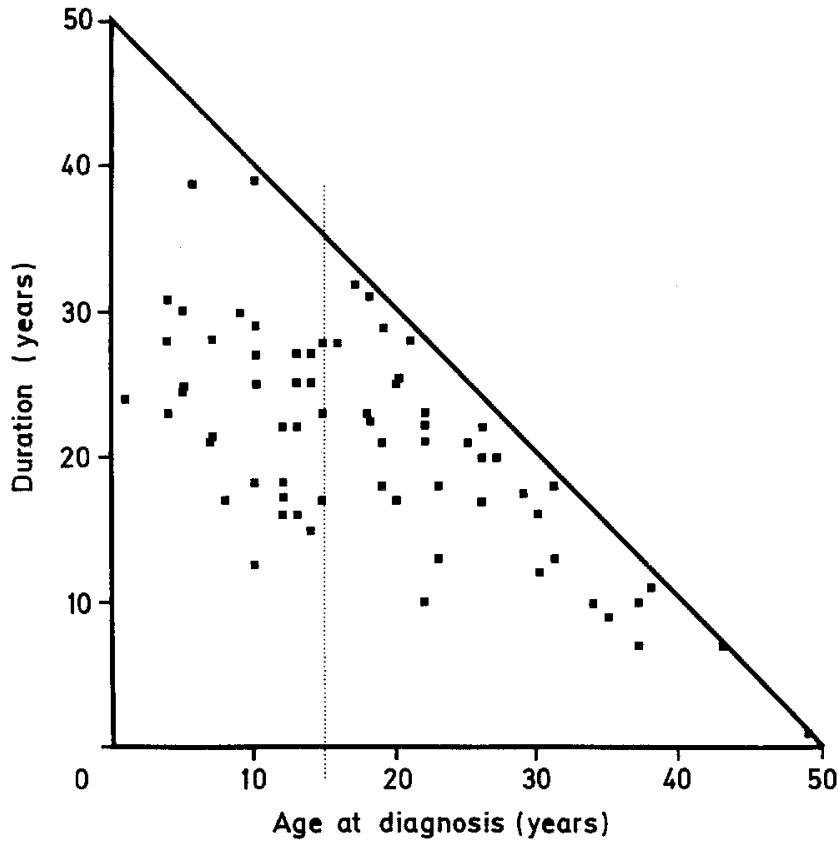

Fig. 2. Relationship of age at diagnosis of diabetes and its duration at the time of death

Table 2. Deaths from renal disease in diabetic patients diagnosed before age 15 years

\begin{tabular}{|c|c|c|}
\hline $\begin{array}{l}\text { Duration of diabetes } \\
\text { (years) }\end{array}$ & Number of deaths & Expected deaths \\
\hline $0-9$ & \multirow{3}{*}{25} & \multirow[b]{2}{*}{18.2} \\
\hline $\begin{array}{l}10-19 \\
20-29\end{array}$ & & \\
\hline $30+$ & & 11.8 \\
\hline Total & 30 & 30.0 \\
\hline
\end{tabular}

The difference between the numbers of deaths observed and expected is significant $\left(\chi^{2}(c)=6.49,0.05>p>0.01\right)$. The expected values were calculated assuming: (1) there would be no deaths from renal disease under 10 years duration of diabetes and (2) deaths from renal disease would be equally distributed by duration of diabetes. But these expected values slightly overestimate the difference because all those aged $0-14$ years at diagnosis would not be expected to reach 50 years of age. However, the result would still remain significant provided not more than $20 \%$ of those with duration over 29 years were expected to die from other causes before 51 years of age

Table 3. Nephropathy and proteinuria in patients diagnosed under age 31 years

\begin{tabular}{lllll}
\hline & $\begin{array}{l}\text { Renal } \\
\text { failure } \\
\text { deaths }\end{array}$ & $\begin{array}{l}\text { Cardio- } \\
\text { vascular } \\
\text { deaths }\end{array}$ & $\begin{array}{l}\text { All other } \\
\text { deaths }\end{array}$ & $\begin{array}{l}\text { Total } \\
\text { deaths }\end{array}$ \\
\hline Nephropathy & 59 & 24 & 15 & 98 \\
No proteinuria & - & 29 & 53 & 82 \\
Proteinuria only & - & 4 & 3 & 7 \\
Proteinuria not known & - & 9 & 22 & 31 \\
\hline Total & 59 & 66 & 93 & 218 \\
\hline
\end{tabular}

a 'Proteinuria only' refers to those patients in whom proteinuria was recorded but whose retinal status was not known. All patients described as 'nephropathy present' were known to have retinopathy 
The presence of vascular disease (i.e. deaths from cardiovascular disease, together with symptomatic cardiovascular disease in those dying from non-vascular causes) in patients with and without nephropathy and of comparable duration ( $>20$ years) was compared, and was found to be similar in the two groups: it was present in 36 of 68 of nephropathy patients $(53 \%)$ and 26 of 38 without proteinuria (68\%).

\section{Discussion}

Nephropathy is a very common complication in diabetic subjects diagnosed under 31 years of age. It is present in almost half of these patients at the time of death, and is responsible for over one-quarter of the deaths. Diabetic subjects diagnosed above this age more frequently die from cardiovascular disease, although uraemia from nephropathy is nevertheless responsible for about onesixth of all deaths in those under age 50 years. Similar observations were made from the Joslin Clinic by Marks [1] who reported that $42 \%$ of deaths of diabetic subjects diagnosed under 20 years of age were from renal failure. Mortality studies do not, of course, indicate the actual proportion of diabetic patients who die from a specific cause, since survivors are not taken into account. Observations from Denmark [2] describing the fate of diabetic patients diagnosed under age 31 years suggest that, overall, about one-fifth of them die from nephropathy.

Most deaths from nephropathy occur after less than 30 years of diabetes, and very few after 30 years. If the development of nephropathy depended only on increasing duration of diabetes the number of deaths would be expected to increase as duration increased, but this is not the case. In Denmark, Christiansen et al. [6] has shown that the annual incidence of proteinuria decreases markedly after 30 years of diabetes. It is also clear from the data of Marks [1] that deaths from that nephropathy are less common after 30 years of diabetes, and Knowles [7] showed that the percentage risk of proteinuria did not increase further after 30 years duration of disease. It is possible that insulin-dependent diabetic patients are heterogenous, and that some are more, some less prone to develop nephropathy. The reasons for this are not known and it is still uncertain whether genetic factors may be important in the development of diabetic complications.

Overall, male deaths $(59 \%)$ were commoner than those among women, and this together with the slight excess of male childhood diabetes may account for the small predominance of men to women in a ratio of $1.3: 1$ amongst the renal failure deaths. Reports on the sex incidence of nephropathy vary. While Thomsen [8], in his major report, found equal numbers of men and women, more recent work from Denmark [9] has again shown a predominance of diabetic men with impaired renal function with a male: female ratio of $1.75: 1$. The reason for this difference is not known.

Complications of diabetes in end-stage renal failure cases are often severe and may make treatment difficult, or at times even unwise. Retinopathy, usually proliferative, is always present and indeed, if it is absent, renal failure is almost certainly not due to diabetic glomerulosclerosis [10]. One-third of those dying from diabetic nephropathy were blind and a further one-third had impaired vision. These observations are similar to those reported from Minneapolis when 33 out of $133(25 \%)$ were found to be blind in both eyes just before transplantation [11]. Retinopathy appears to accelerate during the year or two before transplantation [12] and it has been suggested that its progression is to some extent reduced after transplantation compared with its course during haemodialysis [11].

Major arterial disease is a common cause of death amongst young long-term diabetic patients. It is responsible for most of the deaths in those patients with nephropathy who do not die from uraemia, and accounts for many deaths even in the absence of diabetic renal disease; it also accounts for an excessive number of deaths after transplantation [13]. Many patients with end-stage nephropathy starting dialysis or undergoing transplantation, even young women, have severe arterial disease; similar observations have been made after coronary angiography [14]. Whether the presence of nephropathy in a diabetic alters the likelihood of developing major arterial disease is not known; however, observations from the present study suggest that its prevalence is probably similar in those with and without nephropathy, although these observations need to be confirmed.

Patients with nephropathy also suffer from severe foot problems and amputations. In the present study, five of the 69 patients had suffered some form of lower limb amputation, and one patient who had had neither dialysis nor transplantation needed amputation of fingers. Reports from Minneapolis also comment on these problems, noting that about one patient in five has an amputation after transplantation and that amputation of fingers occur almost exclusively amongst diabetic subjects $[4,9]$. Neuropathy also contributes to problems of the diabetic foot, and the large number ( $26 \%$ ) of foot ulcers is additional cause for concern. Some degree of neuropathy is probably present in almost all terminal nephropathy cases [12] although it is not always severe.

This study describes the contribution of nephropathy to the mortality of diabetic patients dying under age 50 years and ascertains the proportion and severity of other complications in this group. From the method of investigation, it is likely that the records overestimate deaths from diabetic complications and underestimate deaths from unrelated causes where diabetes may not have been mentioned on the death certificate. Nevertheless, it probably represents the closest approximation which can be made. We estimate that if patients with strokes or amputations (12 cases) or with other 
overwhelming diabetic complications (blindness and foot ulceration; four cases) were excluded from consideration, then about threequarters of the patients with renal failure (53 out of 69) might have merited transplantation or dialysis. Older patients tend to have more complications and are generally less suitable for these procedures than those who develop uraemia when relatively young: this is reflected in the results of transplantation which are best in those under 30 years of age.

The total number of deaths ascertained by this study is, however, a considerable under-estimate, not only because cases may have been missed by the co-ordinators, but also because where diabetes was not directly responsible for death it may have been omitted from the certificate. It is thus difficult to discover the exact annual number of deaths from diabetic renal failure. However, if approximately one-fifth of young diabetic patients die from renal failure [2] and since the British Diabetic Association register [15] now records 1500 new diabetic subjects under 16 years of age each year, one would expect considerably more than 300 diabetic renal failure deaths each year.

Acknowledgements. We are grateful to Servier Laboratories for supporting a research fellowship for Dr. A. Moloney and to Mrs. G. B. Watkins for statistical advice.

\section{References}

1. Marks HH (1965) Longevity and mortality of diabetics. Am J Public Health 55: 416-423

2. Deckert T, Poulsen JE, Larsen M (1978) Prognosis of diabetics with diabetes onset before the age of thirty one. Diabetologia 14 : 363-370

3. Rao TKS, Hirsch S, Arram MM, Friedman EA (1980) Prevalence of diabetic nephropathy in Brooklyn. In: Friedman EA, L'Esperance FA (eds) Diabetic renal-retinal syndrome. Grune \& Stratton, New York, pp 205-207

4. Goetz FC, Kjellstrand CM (1979) The treatment of diabetic kidney disease. Diabetologia 17:267-281
5. Tunbridge WMG, on behalf of the Medical Services Study Group and the British Diabetic Association (1981). Deaths in diabetics under 50 years of age. Lancet 2: $569-572$

6. Christiansen JS, Andersen AR, Andersen JM, Deckert T (1983) Diabetic nephropathy - prognosis and factors related to development. In: Irsigler K, Kunz KM, Owens DR, Ragal H (eds) New approaches to insulin therapy. MTB Press, Lancaster (in press)

7. Knowles HC (1974) Magnitude of the renal failure problem in diabetic patients. Kidney Int 6 (Suppl 1): $52-57$

8. Thomsen AC (1965) The kidney in diabetes mellitus. Munksgaard, Copenhagen

9. Andersen AR, Andersen JK, Christiansen JS, Deckert T (1978) Prognosis for juvenile diabetics with nephropathy and failing renal function. Acta Med Scand 203: 131-134

10. Deckert T, Poulsen JE (1968) Prognosis for juvenile diabetics with late diabetic manifestations. Acta Med Scand 183:351-356

11. Ramsay RC, Cantrill HL, Kinyoun JL, Knobloch WH, Sutherland DER, Kjellstrand CM, Najarian JS, Goetz FC (1980) Visual status in diabetic renal failure. In: Friedman EA, L'Esperance FA (eds) Diabetic renal-retinal syndrome. Grune \& Stratton, New York, pp 309-315

12. Barbosa J, Burke B, Buselmeier TJ, Carpenter AM, Goetz FC, Harris J, Kennedy WR, Kjellstrand CM, Michael AF, Najarian JS, Recker L (1974) Neuropathy, retinopathy and biopsy findings in transplanted kidney in diabetic patients. Kidney Int 6 (Suppl 1): 532-536

13. Najarian J, Sutherland D, Simmons R, Howard R, Kjellstrand C, Ramsay R, Goetz FC, Fryd D, Sommer B (1979) Ten year experience with renal transplantation in juvenile-onset diabetics. Ann Surg 190: 487-500

14. Bennett WM, Norman DJ, Barry JM (1980) Coronary artery disease in end-stage diabetic nephropathy. In: Friedman EA, L'Esperance FA (eds) Diabetic renal-retinal syndrome. Grune and Stratton, New York, pp 219-227

15. Bloom A, Hayes TM, Gamble DR (1975) Register of newly diagnosed diabetic children. Br Med J 3: 580-583

Received: 16 October 1981

and in revised form: 10 May 1983

Dr. P. Watkins

Diabetic Clinic

King's College Hospital

Denmark Hill

London SE5 9RS, UK 